\title{
Characteristic Evaluation and Scenario Study on Fast Reactor Cycle in Japan
}

\author{
Hiroki Shiotani, Kiyoshi Ono and Takashi Namba \\ Japan Atomic Energy Agency (JAEA) \\ Japan
}

\section{Introduction}

Today, Japanese nuclear energy faces a period of great change. After the start up of plutonium recycling in LWR (light water reactor) and groundbreaking of MOX (Mixed OXide) fuel fabrication plant (J-MOX), Rokkasho reprocessing plant is preparing its operation. Regarding Gen IV nuclear energy system, a joint team of Japan Atomic Energy Agency (JAEA) and the Japan Atomic Power Company (JAPC) and related parties has been conducting Fast Reactor Cycle Technology Development Project (FaCT Project) since 2006. It has been a Japanese political choice to take a step toward Fast Reactor (FR) commercialization in the middle of this century. It will be reviewed by the government of Japan in response to the recent accident at Fukushima Daiichi Nuclear Power Station. In $\mathrm{FaCT}$ project, besides the facility design studies and element technology development, the characteristic evaluations and scenario studies have been conducted including the methodology development to confirm and give suggestions on basic directions of the research and development $(\mathrm{R} \& \mathrm{D})$.

\section{FaCT project and evaluation tool}

In this section, the outline of FaCT project is described including the background Japanese nuclear policies firstly. Then, a new evaluation code developed for FaCT project is described as the basic infrastructure for the strategic studies and evaluations in future Japanese nuclear fuel cycle.

\subsection{Outline of FaCT project}

FR cycle technology is capable of reprocessing spent fuels and utilizing recovered plutonium and uranium as new fuels effectively. It also has the potential to provide Japan with long-term stable energy supply and contribute to reducing the potential harmfulness of radioactive waste. Therefore, with the aim of putting FR cycle technology into practice at an early stage, JAEA, in cooperation with electric utilities, is working on $\mathrm{FaCT}$ project which mainly targets a combination of the Sodium-cooled FR with oxide fuel, advanced aqueous reprocessing, and the simplified pelletizing fuel fabrication since 2006. In 2010, taking the transitional period from LWR cycle to FR cycle into consideration, we reviewed and revised the procedures of R\&D on reprocessing technology deployment from 2011 onward. Outline of FaCT project is shown in Figure. 1. 


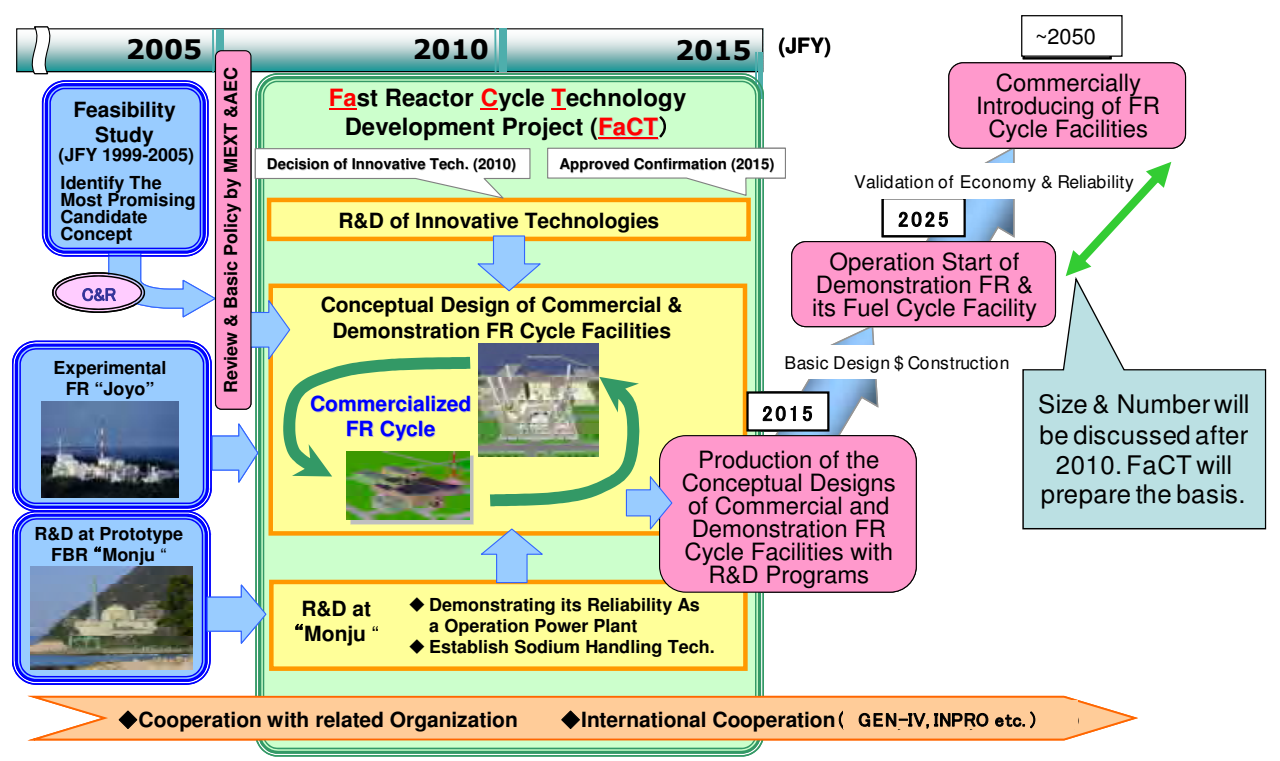

Fig. 1. Outline of FaCT project

The national policy guidelines such as "Energy Basic Plan" articulates that R\&D on FR cycle technology should be promoted aiming for the start-up of demonstration FR around 2025 and its introduction on a commercial basis before 2050. Based on these national policies, in 2015, FaCT project aims to present conceptual designs of both commercial and demonstration facilities of FR cycle, which has capability to acquire the feature that nextgeneration nuclear energy system must fulfill from the viewpoints of safety, economics, environmental impact, resource utilization efficiency and proliferation resistance, and R\&D plan towards its commercialization. In order to put those commercial and demonstration facilities in practice, promoting introduction of innovative technology, FaCT project is conducting element technology development and its subsequent design studies which are identified with 13 R\&D issues (or 10 techniques regrouped for adoption judgment) on reactor system and $6 \mathrm{R} \& \mathrm{D}$ issues on reprocessing system and fuel fabrication system respectively. In 2010, the last year of FaCT project phase 1 starting 2006, we carried out the adoption judgment of innovative technologies and the performance criteria assessment of FR cycle system, which reflect the results of the adoption judgment, toward the performance target. These results are being assessed by the Ministry of Education, Culture, Sports, and Technology (MEXT) and the Ministry of Economy, Trade and Industry (METI). Although the future FaCT plan will be reconsidered due to the accident at Fukushima Dai-ichi nuclear power station, we will progress steadily to realize the commercialization of FR and its fuel cycle in around 2050 while enhancing the safety and reliability of the FR cycle concept.

Meanwhile, we are also conducting R\&D on metal fuel cycle as secondary concept, and plan to carry out from 2011 onward with the international cooperation.

\subsection{Typical Japanese FR deployment scenario}

World's energy consumption is increasing with economic growth and it is expected for nuclear energy to play an important role worldwide to secure the stable energy supply and 
to prevent global warming (reduction of greenhouse gas emission) aiming at realization of sustainable growth. The level 7 accident of International Nuclear Event Scale (INES) occurred at the Fukushima Dai-ichi Nuclear Power Station by the massive earthquake in March 11, 2011 in Japan and some countries began to revalidate nuclear plant safety and conduct a review of their nuclear policies. However, in the U.S., large number of nuclear power plants are planned to be built for the first time in 30 years. In India and China, which maintain high rates of economic growth, it is planned to build additional nuclear power plants to raise the entire nuclear capacity up to about 290GWe and 250GWe, respectively by 2050. In Long-term forecasts conducted by major international agencies concerning energy, such as WEO 2009, ETP2008 and ETP2010 by OECD and IEA, it is projected that nuclear energy will expand in the long-term as a countermeasure against global warming with posing scenarios where conventional measure that only focused on controlling global warming will be replaced by the measure that promotes nuclear energy utilization while limiting greenhouse effect gas emission intensively.

Meanwhile, in 'Basic Energy Plan' decided by the Japanese Cabinet in June, 2010, it is planned to build at least 14 additional nuclear power plants by 2030, domestic nuclear power plant capacity of about $48.8 \mathrm{GWe}$ will rise to about $68 \mathrm{GWe}$. Furthermore, Japan aims at introducing FR cycle on a commercial basis before 2050 as stated in 'Framework for Nuclear Energy Policy' decided by the Cabinet in October, 2005 and in 'Nuclear Energy Nation Plan' approved by the Atomic Energy Commission in March, 2006. The 'Basic Energy Plan' will be reviewed in response to the Fukushima Dai-ich accident. An example of trial calculation is shown in Figure 2, it demonstrates the transition of the nuclear energy composition when FRs (combination of high breeding core with breeding ratio of 1.2 and low breeding core with breeding ratio of 1.03) featured in the FaCT project, are introduced in 2050. Before FR deployment, plutonium recovered from LWR reprocessing plants will be recycled mainly in LWR, and its LWR capacity will be about 10-20GWe. From 2050 onward, if the LWRs with life time of 60 years are replaced by FRs one by one, it takes minimum 60 years for the complete transition from LWR to FR. Or, if the deployment pace of FR becomes slow and it makes the coexistence period of LWR and FR longer, FR cycle can be flexible to deal with the transition from LWR to FR by adjusting FR breeding performance and/or reprocessing plan by itself.

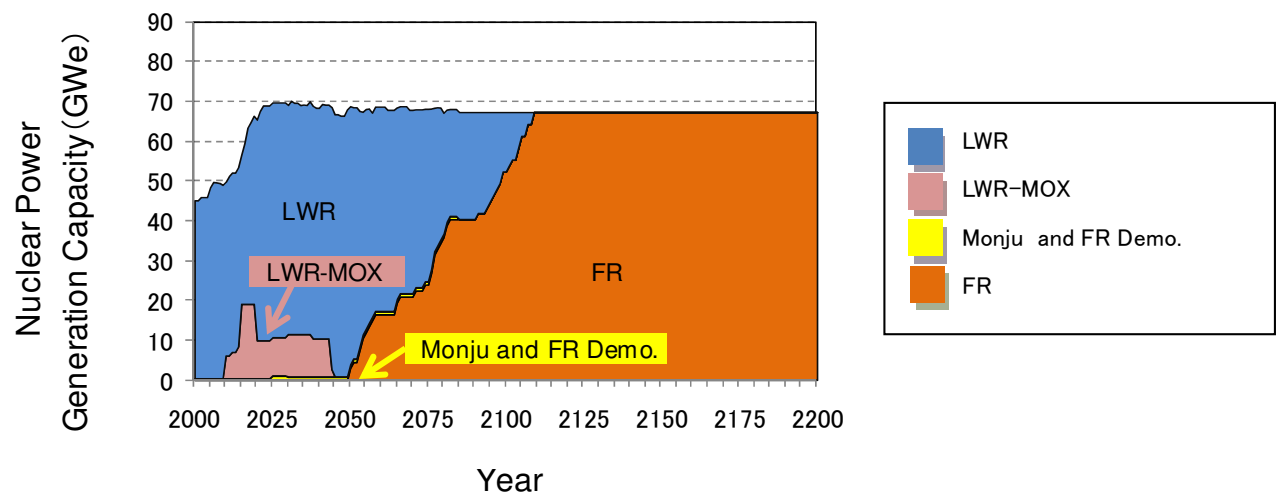

Fig. 2. Long term framework for nuclear energy in Japan (FR deployment in 2050) 
Currently, Japan poses basic nuclear scenario where current LWR cycle transitions completely to FR cycle and it is detailed as follows: 1) the period of LWR existence only, 2) the transition period from LWR to FR, and 3) the equilibrium period of FR existence only. Evaluation of equilibrium cycle is targeted to the third, 'FR equilibrium period'. As the 'FR equilibrium period', when only FR cycle and its fuel cycle exist, continues for long period of time, plutonium composition in new fuels and spent fuels of FR, high-level radioactive waste, and economics will converge to a certain equilibrium value and end up being simple phase, that is ' the state of multiple equilibrium cycle'.

\subsection{Performance evaluation tool both for equilibrium and transient nuclear fuel cycle system}

Regarding the evaluation methodology to seize the comprehensive characteristics of nuclear energy (typically LWR cycle to FR cycle), the methodology is aimed at: 1) performing comprehensive evaluation of nuclear energy business based on both transient period and equilibrium period using the systematically structured data model of nuclear facilities; 2) being a fundamental deliberation evaluation tool providing various information on $R \& D$ and design study of nuclear energy system in the future. Evaluating dynamic nuclear energy system in the transient period as well as FR cycle in equilibrium status, we employ time-series evaluation method mainly dealing cash-flow or mass- flow regarding atomic energy directly to reflect transition of target nuclear energy system.

From the view point of economic evaluation, a large-scale calculation system is required because it is necessary to express cash-flow or mass-flow of every facility, such as nuclear power reactor, fuel fabrication facility, reprocessing facility, waste disposal facility, etc. in the life cycle consisting of construction, operation and decommissioning and to calculate the amount of waste or cash-flow from nuclear system overall through adding up those cashflows or mass-flows.

With the knowledge of management engineering, this method was built based on the concept of supply-chain management (SCM) for nuclear fuel cycle with the consideration of business risk of nuclear fuel cycle which was carried out at the first stage of FS phase II. Using the calculation tool employing time-series multi-dimensional evaluation method basically developed in the final evaluation of FS phase II, we started development of the system intensively and obtained sufficient functions to coordinate evaluation and review the design of FaCT project. Thus the SCM code is at present developed as both performance criteria evaluation tool and detailed transition period evaluation tool.

This method is network-flow type dynamic analysis model to simulate overall nuclear energy business by forming nuclear facilities which makes up nuclear energy system. Object-oriented design and analysis technique was used to enhance the system flexibility and extendibility of the code. It covers almost all the facilities in Japan from the beginning of the nuclear energy utilization and FR cycle equilibrium state in future. It can conduct burnup calculation of nuclear fuel in nuclear power plants as well as decay calculation of nuclear material in fuel cycle facilities including actinides, fission products, and other nuclides although it only uses the ORIGEN-2 code with the libraries based on JENDL-3.3. Although the evaluation started at the present in the figure, it should be started the calculation at the beginning of the use of nuclear energy. With the capability described above, it enables to evaluate both the amounts and compositions of materials/wastes. Furthermore it can assess cost (economic efficiency) at all facilities in Japanese FR deployment scenario (installed capacity) shown as Figure 2. 


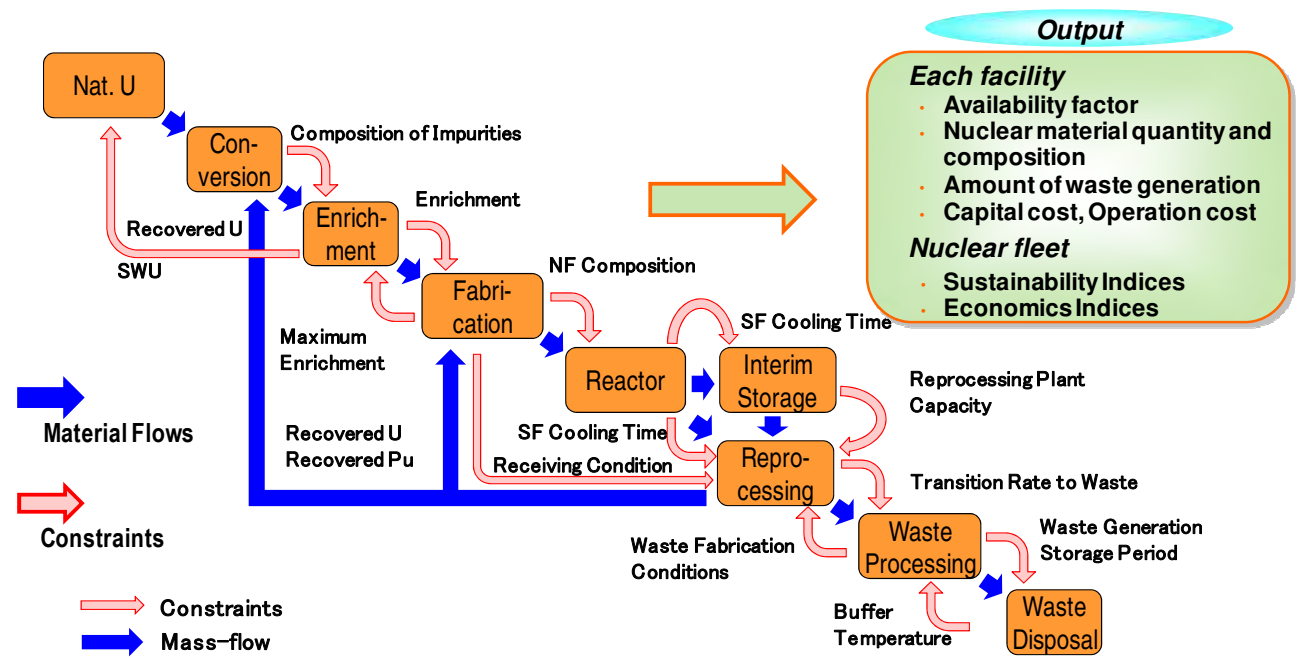

Fig. 3. Nuclear supply chain and SCM code

Figure 3 shows the relationship between the facilities in nuclear fleet. For example, the effects from the differences of breeding ratio of FR, reprocessing plant, and Am-Cm recycling on characteristics from developmental targets influences the material flow from reprocessing plant. With the object oriented design feature and mechanism that conveys information and materials via the interface among highly independent facilities, it is easy to place improvements on a facility by itself according to needs. Furthermore, the SCM code enabled us to simulate nuclear fuel cycle overall in the process of procurement, dispose and transportation of material from the upper to lower facilities without any major change with facility data that indicates basic characteristics of nuclear facilities according to the provided schemes and scenarios as the assumption of analyses by user in timely manners.

\section{Characteristics evaluation of equilibrium FR cycle and scenario evaluation}

In this section, evaluation on Japanese nuclear fleet in FaCT project is described mainly by SCM code code. It covers almost all the facilities in Japan from the beginning of the nuclear energy utilization and FR cycle equilibrium state in far future.

\subsection{Characteristics evaluation of equilibrium FR cycle}

The characteristics evaluations on FR cycle in equilibrium status related to the development target of FaCT project, which are, economics, environment reservation, radioactive waste management, uranium resource utilization efficiency, and proliferation resistance. The recent results of the design studies of FR cycle reflected in the evaluations. In those evaluations, single reactor and related fuel cycle were supposed to be evaluated.

\subsubsection{Evaluation method of equilibrium cycle}

The characteristics of system will be defined more clearly in its equilibrium state because FR cycle is closed cycle which has limited mutual actions with outside. That means evaluation 
of equilibrium cycle is suitable method for conducting comparative evaluations on candidate concepts having different characters with common manner. Furthermore, it requires few preconditions aside from design result of FR cycle since mutual actions (mass balance) with outside of FR cycle are small. Therefore, it will be relatively easy to apply strict methods to evaluate and lessen the uncertainty which affect the characteristics of FR cycle. In mass balance calculation, more sophisticated methods than those used in timeseries evaluation are applied and its calculation result is stable. The flexibility of SCM code enabled us to treat FR cycle in equilibrium state and mixture of LWR cycle and FR cycle transient state with unified manner in the same code. We are conducting the evaluations of accumulative natural uranium demand, waste generation and economics for the state of multiple equilibrium cycle'.

\subsubsection{Accumulative natural uranium demand}

Although the analysis for cumulative natural uranium demand treats a transient characteristic of nuclear fleet, natural uranium demand evaluation result is written here because it is raised as one of the essential characteristics of FR cycle system. Figure 4 shows Japan's accumulative natural uranium demand of some scenarios, such as 'LWR once through', 'Pu recycling in LWR' and 'FR deployments' in 2040, 2050 and 2060. In the cases of LWR once through and Pu recycling in LWR, accumulative natural uranium demand in the period of 2007 through 2120 will be about 1.5 million tons and 1.15 million tons, respectively. In addition, if FRs with breeding ratio of 1.1 or 1.2 are deployed starting in 2050, all LWRs will be replaced to FRs completely around 2130, enabling accumulative uranium demand to be saturated at about 0.8 million tons level which accounts for $5 \%$ of conventional uranium resources (total about 16.7 million tons). Consequently, there will be no need to import natural uranium from other countries. In the case of 'LWR once through'

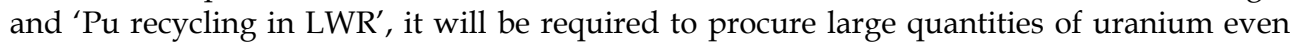
after the late $21^{\text {st }}$ century in which fears over depletion of uranium resource will be foreseen worldwide. On the other hand, in 'deployment of FR' case, it will be unnecessary to import uranium and will lead to an enhancing of energy security.

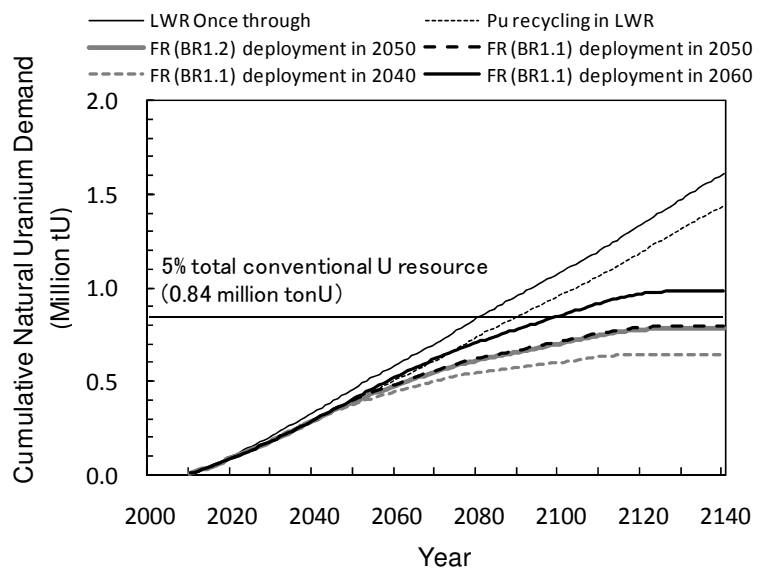

Fig. 4. Accumulative uranium demand in Japan 


\subsubsection{Waste generation}

Nuclear energy supply chain is complicated and great deal of radioactive waste is handled in it, thus sufficient safety measure and waste management should be established at the nuclear facilities to prevent from influencing surrounding environment and residents. In particular, we have to address the challenges to treat and dispose HLW generated in reprocessing plant safely. Figure 5 indicates the amount of HLW unit of electricity generated and usable years of final disposal site. In current LWR cycle, HLW, namely vitrified wastes are produced with the amount of 30 canisters during the operation of LWR with 1GWe for a year. While, in the future FR cycle case, it reduces the amount of vitrified waste by $20 \%$ compared with the current LWR cycle because of high thermal efficiency of FR and reduction of pyrogenic FP production. By reflecting foundational R\&D result concerning FP recycle in addition to the minor actinides recycle, it has possibility to achieve drastic reduction of HLW and longer-use of disposal site. Figure 6 shows chronological changes of potential harmfulness (relative values) of HLW (spent fuel (SF) and vitrified waste) in the same amount of electricity generated for each case. After 1000 years later from being discharged from nuclear reactor, in the vitrified waste produced from 'Pu recycling in LWR' case in which most of uranium and plutonium are recycled, potential harmfulness will be reduced to $1 / 8$ of that of spent fuel which is disposed directly in 'LWR once through' case. Moreover, in FR cycle, minor actinides are also recycled in addition to uranium and plutonium, enabling the potential harmfulness to be reduced to $1 / 30$. Meanwhile, the potential harmfulness of HLWs generated in each case are compared with the potential harmfulness of natural uranium required to produce the same amount of electricity generated as each case, which is indicated by the red dashed horizontal line in Figure 6. It will take 100,000 years for the potential harmfulness of direct disposed spent fuel to reduce to the same level with that from natural uranium, 10,000 years for the vitrified waste from LWR cycle, and a couple of hundred years for the vitrified waste from FR cycle. Recycling minor actinides in FR cycle enables us to reduce the potential harmfulness and environmental burdens caused by HLW.

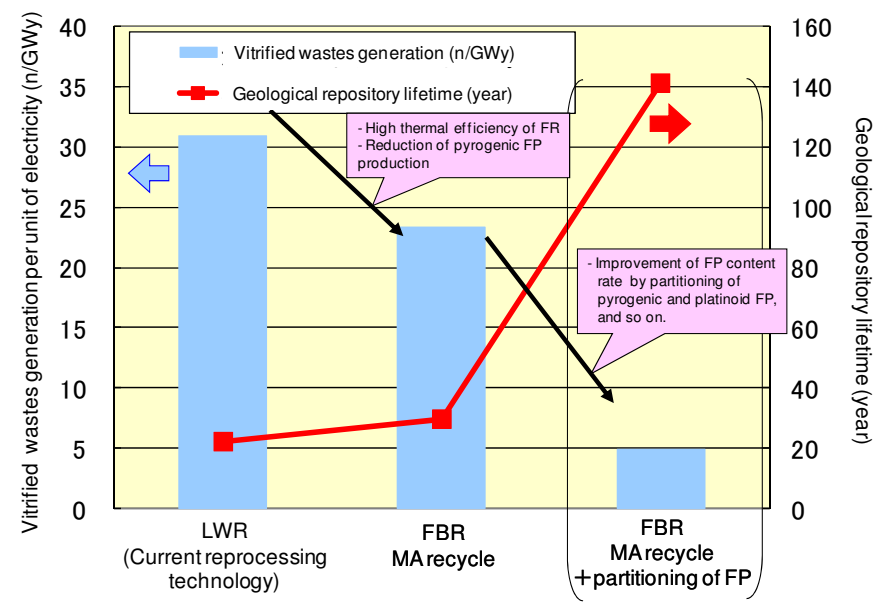

Fig. 5. HLW generation and usable years of final disposal site in Japan 


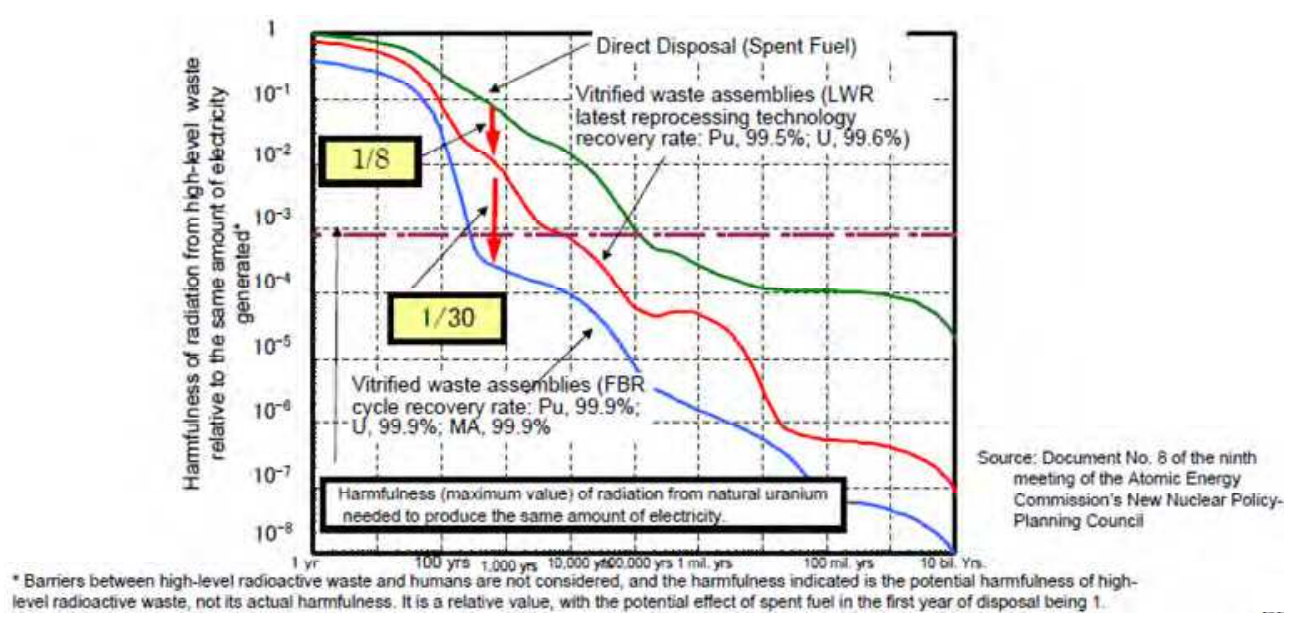

Fig. 6. Harmfulness of HLW (spent fuel and vitrified waste)

\subsubsection{Economics}

We are aiming at economics improvement due to a reduction of amount of material by adoption of innovative technologies toward commercialization before 2050 since FR cycle should be competitive in economy to become basic electric source in the future. Figure 7 shows estimation of the generation costs of current LWR, future LWR and Future FR (breeding ratio of 1.1). The generation cost of future LWR will reduce to $60 \%$ of that of current LWR by improvement of capacity factor and reduction in unit construction cost of reactor. If FR (NOAK) provides superior performance as designed, it will be able to compete with future LWR economically by the effect of high thermal efficiency and adoption of high burn-up fuel, although the unit construction cost of reactor may be little higher. The total cost consists of capital cost, operating cost and fuel cost accounting for about a third each. As regard to FR, considering the effect of drop down of capacity factor and increase of the unit fuel cycle cost posed by adoption of alternate technologies on the power generation cost, the power generation cost will be almost the same level as that of current LWR. However, it would appear that the FR cycle compete with the future LWR cycle economically.

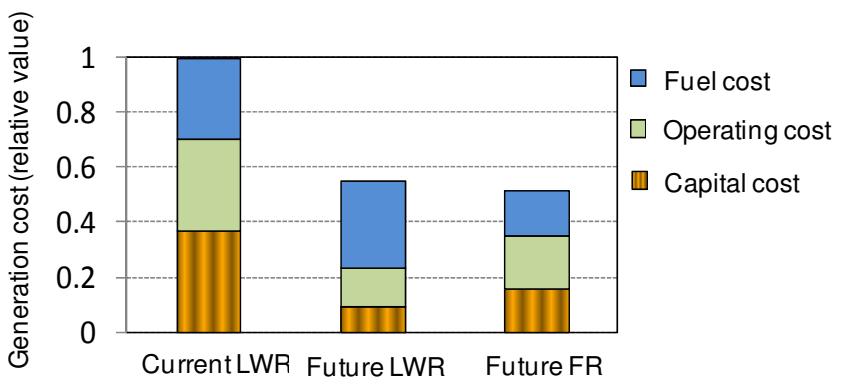

Fig. 7. Comparison of the generation costs between LWR and FR (relative value) 


\subsubsection{Nuclear proliferation resistance}

As nuclear materials are used as fuels in nuclear energy, we must sweep away the concerns over nuclear proliferation. Japan has been applied comprehensive safeguards including supplementary protocols and becomes an international model country. In addition, toward a commercialization of FR cycle, it is making effort to lead the future nuclear nonproliferation models by concept study for the process in which uranium will be constantly accompanied by plutonium and minor actinides while developing state-of-art technologies of safeguards and physical protections of nuclear materials. As one of the efforts, we are studying for upgrading reactor cores with effective nuclear proliferation resistance and identified the advantage to material barrier which is one of indexes for nuclear proliferation resistance by evaluating isotope composition of plutonium in its spent blanket fuels. The concepts of upgrading reactor cores with effective nuclear proliferation resistance are listed as follows: the core without radial blanket fuels, the core with radial blanket fuels added by plutonium and that added by minor actinides. Figure 8 shows the three core concepts. Regarding the radial blanket fuels added by plutonium, the ratio of $240 \mathrm{Pu} / \mathrm{Pu}$ total in the radial blanket spent fuels is more than $18 \%$ and it meets a criterion for reactor-grade plutonium $\left({ }^{240} \mathrm{Pu} / \mathrm{Pu}\right.$ total $\left.>18 \%\right)$ suggested by Dr. Pellaud. Thus, this design concept alters the plutonium composition to the one without capability being nuclear weapon by adding plutonium into radial blanket fuels, and become the one of measures to enhance the effect of nuclear proliferation resistance.

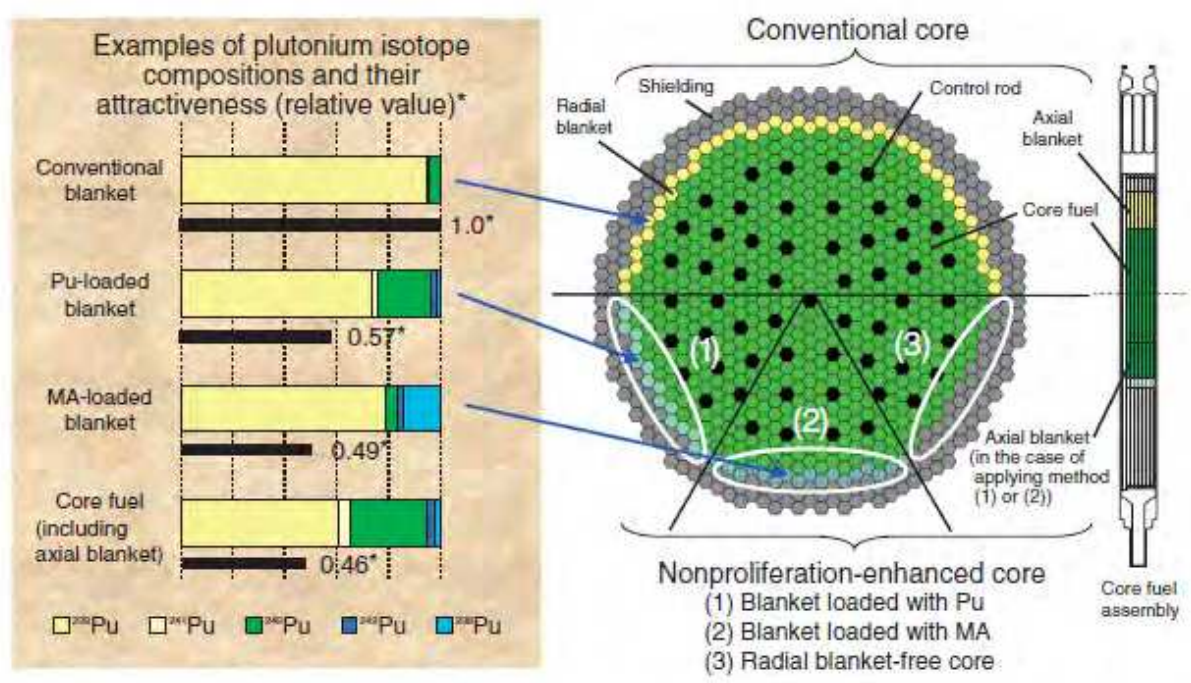

Fig. 8. Three sample core concepts for enhancing the effect of nuclear proliferation resistance (Taken from a figure of “JAEA R\&D Review 2010")

\subsection{Japanese scenario evaluations with advanced analysis tool}

In scenario evaluation, we mainly target at 'the transition period from LWR to FR', which is the second item in the three periods indicated in section 3.1.1. LWRs, FRs and their nuclear fuel cycles coexist in this transition period from LWR to FR. For this reason, in the 
evaluation of 'the transition period from LWR to FR', the results are characterized by the complicated effects of various events and preconditions such as, the FR deployment pace, introduction plan of reprocessing facilities, interim storages of spent fuels, recycle of recovered uranium and so on. In the time-series scenario evaluation, we will optimize the mass-balance among various types of reactors, cycle facilities and fuels and will focus attention on the smooth transition to FR. Since we target at more complex mass-flow comparing to the evaluation of equilibrium cycle, higher leveled and more sophisticated methods must be applied in mass-balance calculation, waste generation, and cash-flow evaluation, etc. In addition, the number of input items and calculation conditions increase and this makes possible for the uncertainty about entire evaluation to be higher than that of equilibrium cycle evaluation. We conduct the evaluations of the changes in nuclear material and radioactive wastes at the same time including plutonium composition, the amount of waste generation and economics on the transition state to the FR cycle.

The scenario analyses were performed to investigate the characteristics of current Japanese nuclear fleet with LWR cycle to the future nuclear fleet with FR cycle. Based on the intensive development of the SCM code to cover both equilibrium and transient status of nuclear fuel cycle, economics, resources, radioactive wastes, and non-proliferation issues and the complex of those issues have been surveyed with consideration of the recent technical progress and events in Japanese society. The authors should begin with the alternation of scenario in recent several years (after the establishment of "Framework for Nuclear Energy Policy" in Japan). Although safety and reliability is raised as one of the important development targets in FaCT project, the consideration of them is not directly reflected in the analyses. Therefore, some important topics in the course of realizing the equilibrium FR cycle state which bring uncertainties to Japanese nuclear fleet were discussed.

\subsubsection{Basic Japanese scenario evaluations including recent change}

The current image of Japanese nuclear energy capacity which is expressed in Framework for Nuclear Energy Policy by Japan Atomic Energy Commission is shown in Figure 9.

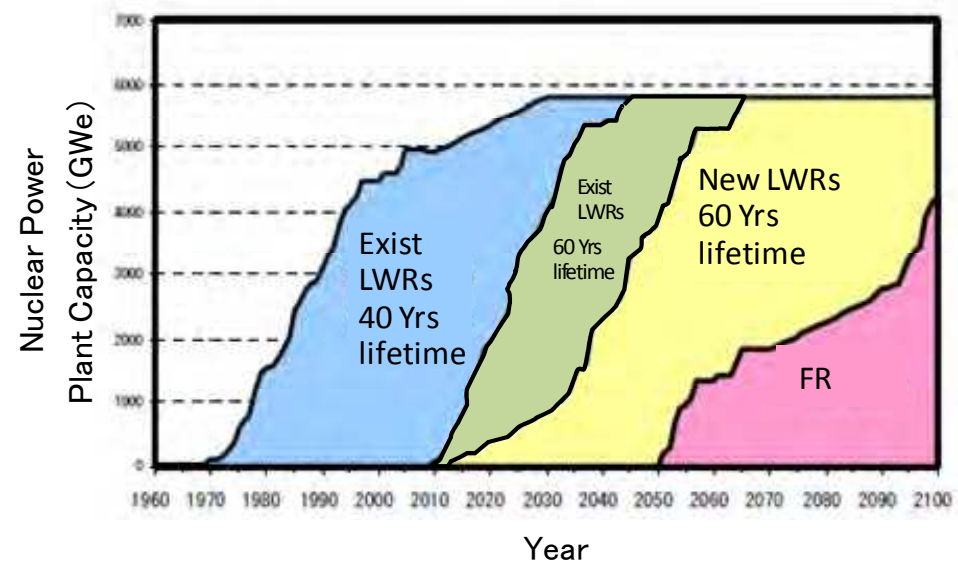

Fig. 9. Nuclear power plant capacity image in the current Framework for Nuclear Energy Policy (Original figure was AEC's HP: Revised by the authors) 
In Figure 9, important points of the nuclear power plant capacity are as follows:

In Japan, the nuclear capacity goal was changed from 58GWe,

The BR=1.1 was supposed for FR for future deployment,

The lifetimes of nuclear power plants were 40 to 60 years,

The reprocessing plants for FR spent fuels will be constructed independently from those for LWR spent fuels.

However, more than five years have passed since the announcement of the current Framework for Nuclear Energy Policy, the circumstances surrounding nuclear fuel cycle including FR cycle also have been changed. The authors discuss several factors which will affect the FR cycle long-term plan and strategy in this section.

First of all, the expectation for nuclear energy has been increased (at least before the accident of Fukushima Daiichi Nuclear Power Station) because it is a just suitable energy to achieve both to urge sustainable economic development and to reduce greenhouse gas emission in the world. In Japan, national energy basic plan published in 2010 insisted that the nuclear energy capacities up to 68GWe by 2030 mainly to meet both of sustainable economic growth and greenhouse gas emission reduction. The increase of the expected nuclear capacity in Japan will urge the breeding needs of FR and related fuel cycle in Japan. Regarding the breeding ratio of $F R, B R=1.1$ is considered as the reference in the current Framework and FaCT project, but FR with higher BR (ex.BR=1.2) which was described in former section is also important in preparedness for the uncertainties of the fuel cycle operation and the possibility of development toward global standard after the governmental evaluation of FS Phase II. Besides, Japanese government, electricity utilities, and manufacturers are making the concept of the next generation LWRs which has 80 years lifetime with the burnup of more than 70GWd/tHM, etc. Additionally, the study on reprocessing facilities subsequent to Rokkasho-Reprocessing Plant (RRP) has started. In the study, dual-purpose (LWR-SF and FR-SF) reprocessing plants were proposed as well as independent single-purpose (for exclusive use) reprocessing plants. Therefore, the authors tried to include those variations in the analysis cases listed in Table 1.

\begin{tabular}{|c|c|c|c|c|c|}
\hline Case & $\begin{array}{c}\text { Capacity } \\
(\mathrm{GWe})\end{array}$ & Core Fuel & Breeding Ratio & $\begin{array}{c}\text { LWR } \\
\text { lifetime }\end{array}$ & $\begin{array}{c}\text { Reprocesing } \\
\text { Plant mode }\end{array}$ \\
\hline Conventional & 58 & $(\mathrm{U}, \mathrm{Pu}, \mathrm{MA})$ oxide & 1.1 to 1.03 & 60 & Single Use \\
\hline Recent (Ref.) & 68 & $(\mathrm{U}, \mathrm{Pu}, \mathrm{MA})$ oxide & 1.1 to 1.03 & 80 & Dual Use \\
\hline $\mathrm{BR}=1.2$ & 68 & $(\mathrm{U}, \mathrm{Pu}, \mathrm{MA})$ oxide & 1.2 to 1.03 & 80 & Dual Use \\
\hline $60 \mathrm{Yrs}$ & 68 & $(\mathrm{U}, \mathrm{Pu}, \mathrm{MA})$ oxide & 1.1 to 1.03 & 60 & Dual Use \\
\hline Single Use & 68 & $(\mathrm{U}, \mathrm{Pu}, \mathrm{MA})$ oxide & 1,1 to 1.03 & 80 & Singlel Use \\
\hline
\end{tabular}

Table 1. Analysis cases reflected basic nuclear energy policy change

In those analyses listed in Table 1, the influence of lifetime extension was largest on future scenarios; change in breeding ratio and future nuclear power plant capacity had some influence. The reprocessing plant mode had a relatively smaller influence, on the whole.

The authors would like to start an analysis treated the meaning of the breeding ratio in the recent context of Japan. The result of FS showed that FR with breeder core of BR1.1 will be enough to deploy FRs smoothly in 80 years for future Japan. The lifetime extension of next generation LWRs to 80years helped reduce the breeding requirement of FRs in future Japan. 
Figure 10 shows the nuclear capacity in Japan for deployment of FR with BR=1.1 with the 80 years lifetime of LWR. The "Dual Use" means a reprocessing plant can be used both for LWR-SF and FR-SF. On the contrary, "Single Use" means a reprocessing plant can be used only for LWR-SF or FR-SF.

However, if some larger uncertainties are considered in scenario study, FRs with breeder core of $B R=1.2$ contributes to offset the risk in Japanese nuclear energy system. Smaller number of FRs with breeder core will be needed for future Japan as is shown in Figure 11. Since cash-flow is the basis for all economics evaluation, Figure 12 shows the total cashflows of FR deployment scenarios with FR of $B R=1.1$ and $B R=1.2$ from Japanese nuclear fleet from 2000 to 2200 . It can be said that the decrease of total power generation cost was JPs from JPY in $B R=1.1$ case from $B R=1.2$, the authors considered the economic merit was not the critical reason to abandon higher breeding ratio, even if the relative low power generation cost for $\mathrm{BR}=1.1$ case acts as an incentive around the deployment stage of FR cycle. Therefore, the room for breeding ratio adjustment corresponds to socio-environment is an evidence of the inherent flexibility in core fuel with fast neutron.

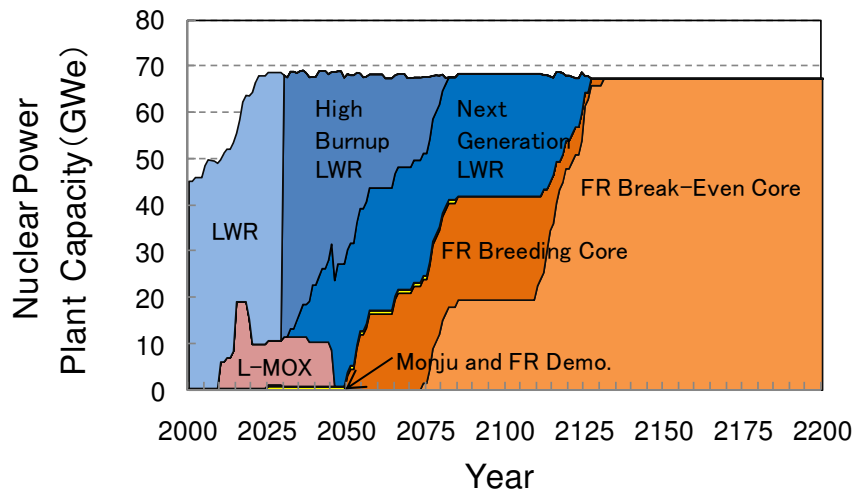

Fig. 10. The nuclear capacity for FR with $B R=1.1$ with the 80 years lifetime of LWR

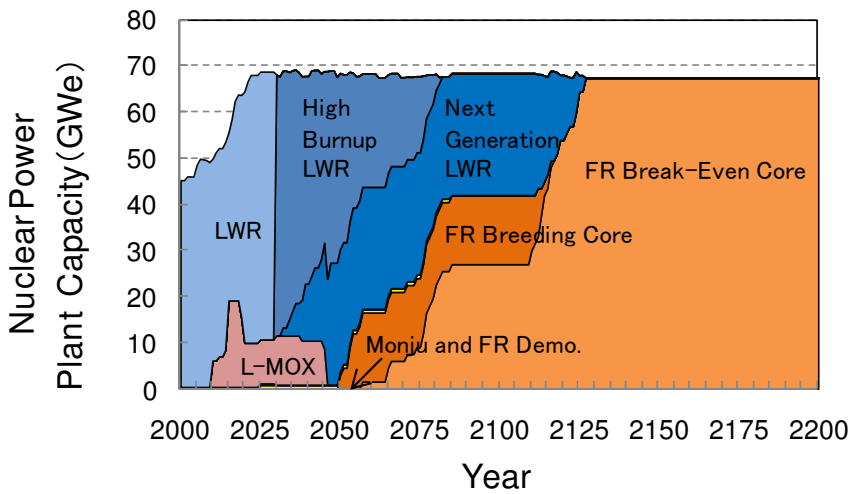

Fig. 11. The nuclear capacity for FR with $B R=1.2$ with the 80 years lifetime of LWR 
As the readers can see several peaks and bottoms from the area chart in Figure 13, the realistic cash-flows are different from simple averaged power generation costs (ex. $2.8 \mathrm{JPY} / \mathrm{kWh}$ for $\mathrm{BR}=1.1$ or $2.6 \mathrm{JPY} / \mathrm{kWh}$ for $\mathrm{BR}=1.03$ ) although they became similar in far future after 2200. The actual dynamic analysis result for electricity generation cost will not usually accord with the simplified or averaged power generation cost of nuclear fleet. In other words, the original cash-flow is the basis of the economic evaluation, it should not be forgotten that simplified electricity generation cost result is basically studied from the ground of cash-flow result in particularly in case of scenario (time-series) evaluation.
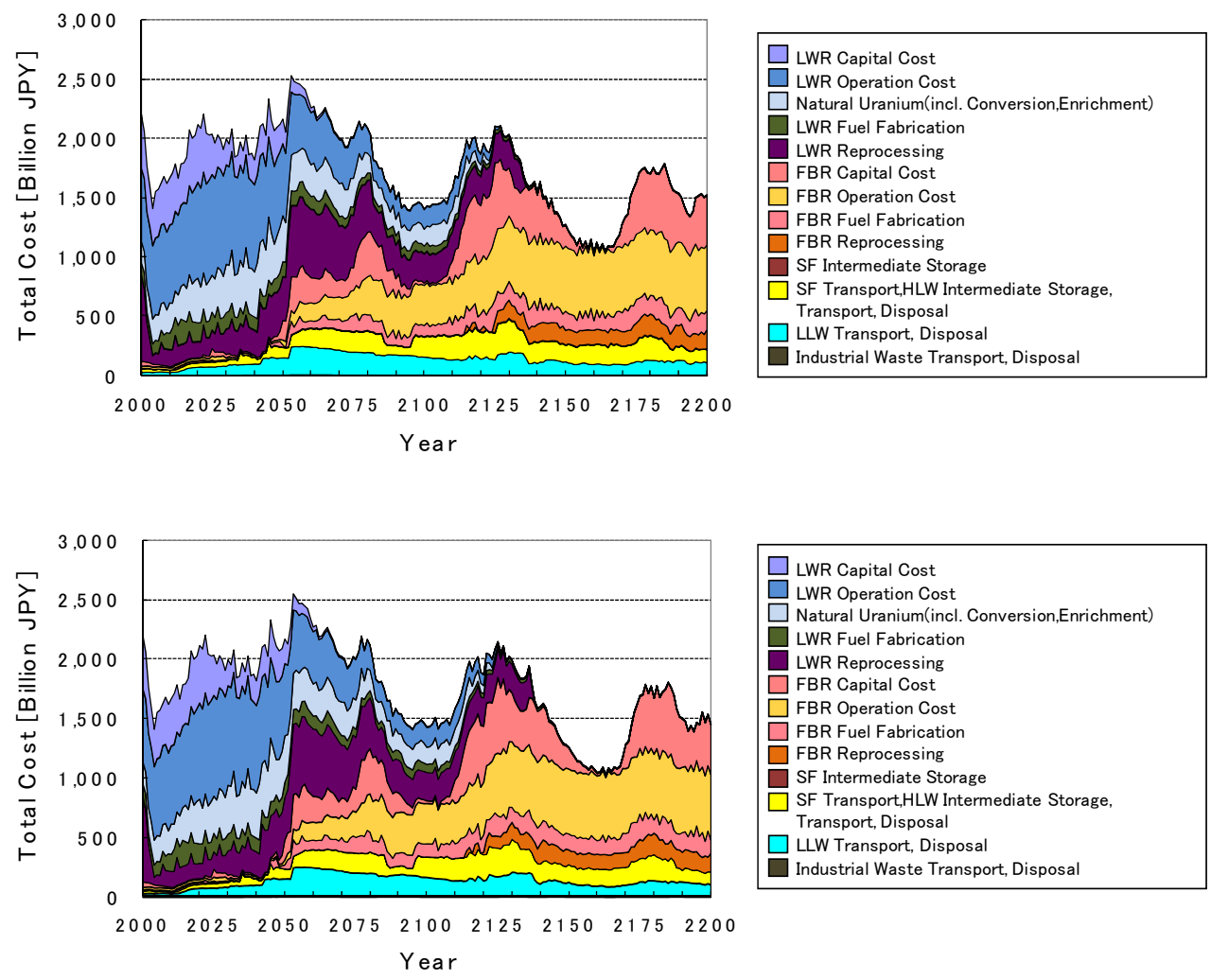

Fig. 12. Total cash-flow of Japanese nuclear fleet for both $(B R=1.1$ and $B R=1.2)$ cases

\subsubsection{Radioactive waste management scenario evaluations}

Another scenario study results showed that the effects of MA recycling on radioactive waste management in FR cycle (reduction of HLWs generation from FR cycle or reduction of heat emission from HLW in FR cycle to cut disposal area). The effect was described in 3.1.3 for equilibrium state of FR cycle. It is caused partly by the nuclear materials in precedent LWR cycle transferred from LWR cycle to FR cycle. The cases listed in Table 2 were analyzed by SCM code on radioactive wastes (mainly HLW) generation. 


\begin{tabular}{|c|c|c|c|c|}
\hline Case & $\begin{array}{c}\text { Capacity } \\
(\mathrm{GWe})\end{array}$ & Core Fuel & Breeding Ratio & $\begin{array}{c}\text { Reprocesing Plant } \\
\text { mode }\end{array}$ \\
\hline U-Pu, Single & 68 & $(\mathrm{U}, \mathrm{Pu})$ oxide & 1.1 to 1.03 & Single Use \\
\hline U-Pu, Dual & 68 & $(\mathrm{U}, \mathrm{Pu})$ oxide & 1.1 to 1.03 & Dual Use \\
\hline TRU, Single & 68 & $(\mathrm{U}, \mathrm{Pu}, \mathrm{MA})$ oxide & 1.1 to 1.03 & Single Use \\
\hline TRU, Dual & 68 & $(\mathrm{U}, \mathrm{Pu}, \mathrm{MA})$ oxide & 1.1 to 1.03 & Dual Use \\
\hline
\end{tabular}

Table 2. Analysis cases with/without MA recycling

Since there was little difference in the results between the single use reprocessing plant case and dual use plant case, the authors did not write the concrete case in the following part. Figure 13 shows the radioactive wastes generation from Japanese nuclear fleet in reference case based on the waste management evaluation by SCM code. There are several peaks in the figure which correspond to the major facilities' decommissioning such as LWR reprocessing plants and nuclear power plants. Although the quantity of HLW is small, it requires large scale facility for disposal and usually focused in disposal site finding issue. Therefore, the influence on HLW from MA recycling is investigated in this section.

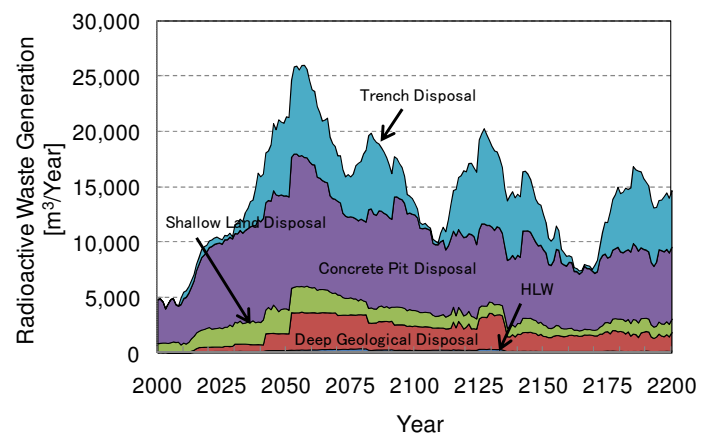

Fig. 13. Radioactive wastes generation from Japanese nuclear fleet

Figure 14 shows the calculated Japanese nuclear power plant capacities according to core type in a typical case without MA recycling. FRs are deployed after 2050 just as same as the reference case explained in 2.2.1. Since the completion of switchover to FR with $(\mathrm{U}, \mathrm{Pu})$ oxide cores were delayed several years from the reference case, total transition period is 84 years from the analyses results. It is explained from the internal conversion ratio difference.

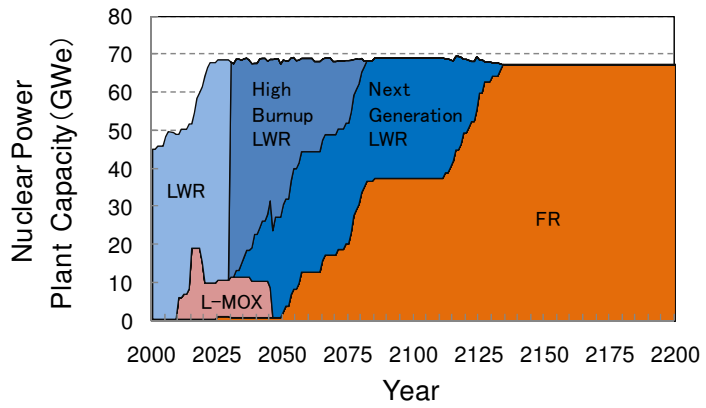

Fig. 14. FR deployment with core of $\mathrm{BR}=1.1$ without MA recycling 
When the total Japanese nuclear fleet is considered, MA recycling has the potential to reduce the quantities of HLW from FR cycle system. Because of the difference in fuel cycle and other discrepancies, it is difficult to compare directly the scenarios with or without MA recycling. Comparing the quantities of HLW generation, Figure 15 was obtained. Though there seems to be little difference (the difference is a kind of complex of causes) in HLW generation from Figure 15, it is expected that the area needed for HLW disposal will be reduced as a result of reduction in decay heat from HLW by MA recovery from raffinate in reprocessing plants. Besides that, MA recycling leaves the possibility for further HLW reduction combined with the introduction of high density FP packing in vitrified waste technology. The reduction of HLW generation will be realistic if the high emission heat nuclides are removed from HLW by the recovery of MAs and/or FPs as described in Figure 16. The difference of HLW generation after 2135 in Figure 17 is the combined effect of MA recycling and high density FP packing in vitrified wastes although the fuel cycle schemes are different because of the existence or non-existence of MA recycling.

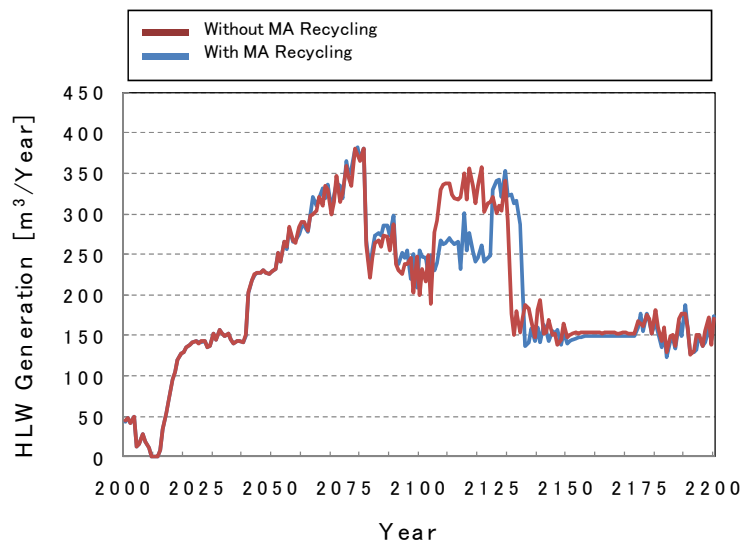

Fig. 15. Comparison of HLW generation from nuclear fleets with and without MA recycling

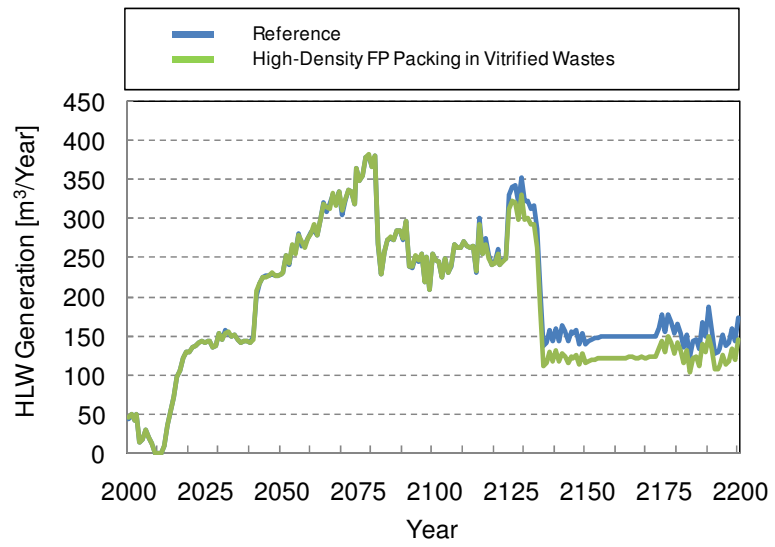

Fig. 16. The effect of MA recycling combined with high-density FP packing in HLW 


\subsubsection{Nuclear non-proliferation scenario evaluations}

As for the scenario study related to non-proliferation, the measures to dope MAs in blanket fuel to improve the non-proliferation characteristics of spent blanket fuel have some issue to be resolved to supply sufficient amounts of MAs to all FRs and its fuel cycle system in Japan. On the other hand, although the measure to add $\mathrm{Pu}$ in blanket may delay FR deployment in future, it is feasible from both of the viewpoints of material supply and of improving material barrier of spent blanket fuel. There are many ideas to enhance proliferation resistance of FR cycle system.

\begin{tabular}{|c|c|c|}
\hline Case & $\begin{array}{c}\text { Core Fuel / Axial Blanket / Radial } \\
\text { Blanket }\end{array}$ & Reprocesing Plant \\
\hline Depleted Uranium Blanket Fuel & $\begin{array}{c}\text { (U, Pu, MA) oxide / } \\
\text { U Oxide / U oxide }\end{array}$ & Single Use \\
\hline Radial Blanket Free Fuel & $\begin{array}{c}\text { (U, Pu, MA) oxide / } \\
\text { U Oxide / - }\end{array}$ & Single/Dual Use \\
\hline MOX Radial Blanket Fuel & $\begin{array}{c}(\mathrm{U}, \mathrm{Pu}, \mathrm{MA}) \text { oxide / } \\
\text { U Oxide / (U, Pu) oxide }\end{array}$ & Single/Dual Use \\
\hline $\begin{array}{c}\text { Radial Blanket Fuel with MA } \\
\text { Doping } \\
\text { (Minoa Actinide) }\end{array}$ & $\begin{array}{c}\text { (U, Pu, MA) oxide / } \\
\text { U Oxide / (U, MA) oxide }\end{array}$ & Single/Dual Use \\
\hline All MOX Blanket Fuel & $\begin{array}{c}(\mathrm{U}, \text { Pu, MA) oxide / } \\
(\mathrm{U}, \mathrm{Pu} \text { oxide /(U, Pu) oxide }\end{array}$ & Single/Dual Use \\
\hline $\begin{array}{c}\text { All Blanket Fuels with MA Doping } \\
\text { (Minoa Actinide) }\end{array}$ & $\begin{array}{c}\text { (U) PA) oxide / } \\
(\mathrm{U}, \mathrm{MA}) \text { oxide / (U, MA) oxide }\end{array}$ & Single/Dual Use \\
\hline
\end{tabular}

Table 3. Analysis cases for non-proliferation improvement core

The analysis cases listed in Table 3 reflect the authors' concern on the measures to apply to the Pu in blanket SF of FR. In Case-1, called the "Radial Blanket Free Core" concept, the radial blanket is replaced by a steel reflector, In Case-2, the radial blanket is fabricated with $\mathrm{Pu}$ in low isotope enrichment so that the plutonium produced in the radial blanket will have a low-fissile ratio. In Case-3 the radial blanket fuel is doped MA, which reduces the attractiveness because of the heat generation from $\mathrm{Pu}-238$. The maximum MA ratio of new core fuel was assumed to be $5 \mathrm{wt} \%$ which was almost recovered from spent LWR fuels although the MA ratio of new core fuel in the equilibrium state FR cycle. In Case- 4 , the radial blanket is fabricated with $\mathrm{Pu}$ in low isotope enrichment so that the plutonium produced in the radial blanket will have a low-fissile ratio. In Case- 5 the radial blanket fuel is doped MA, which reduces the attractiveness because of the heat generation from Pu-238. The maximum MA ratio of new core fuel was assumed to be $5 \mathrm{wt} \%$ which was almost recovered from spent LWR fuels although the MA ratio of new core fuel of FR in the equilibrium state is considered as about one per cent.

The nuclear power plant capacities of all MOX blanket fuel case and all blanket fuel with MA doping case are shown in Figure 17 and figure 18, respectively. No severe influence on smooth introduction of FRs was seen from the analyses. The authors tried to confirm the effect of $\mathrm{Pu}$ addition to blanket fuel through the analyses with SCM code. Dr. Pellaud defined the plutonium including more than $18 \%$ of $\mathrm{Pu}-240$ as "reactor grade" (RG-Pu) as it was explained in 3.1.6. Plutonium in LWR SF meets this RG-Pu condition; it has been used 
globally in commercial manner under the appropriate nuclear material control and management. If the idea that proliferation resistance target of future nuclear energy system should fulfil a kind of "Pareto criterion" in material attractiveness is true, FR cycle system which uses RG-Pu achieves the target. The transition of Pu240/Pu in blanket SF in "All MOX blanket core" case is shown in Figure 19. The Pu240/Pu keeps more or equal than $18 \%$ in general during the lifetime of the reactor though the option somewhat sacrifices the speed of FR deployment.

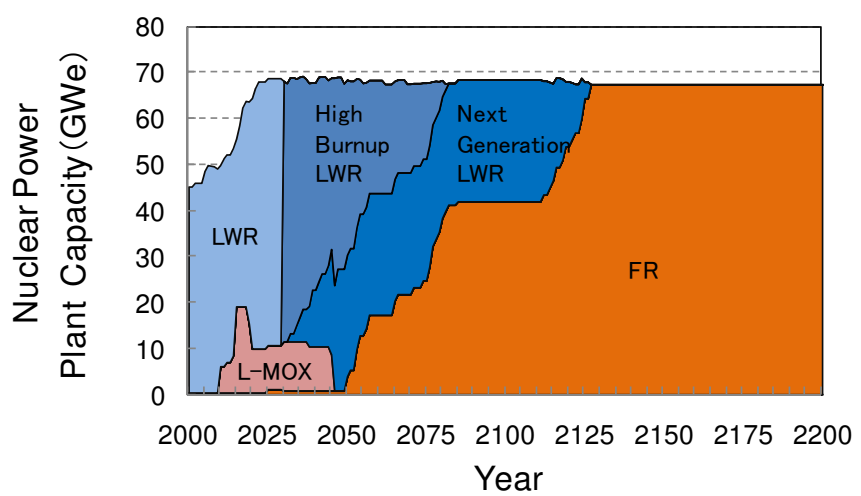

Fig. 17. FR deployment scenario for all MOX blanket case

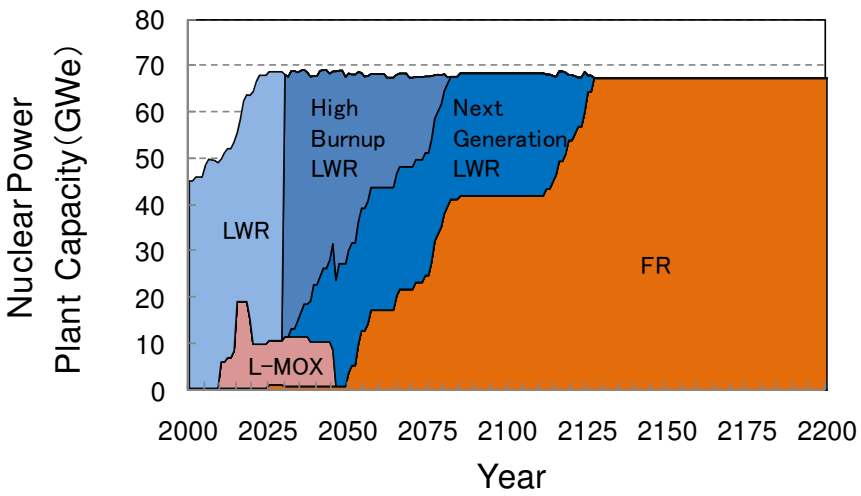

Fig. 18. FR deployment scenario for in all blankets with MA doping case

$\mathrm{Pu}$ isotope content in blanket SF during the transition period from LWR to FR in all MA doping blanket fuel case is shown in Figure 20. As for the period when FRs with radial blanket are installed (before 2090), it looks difficult to meet Kessler's criteria because of the shortage of MAs supply to dope blanket fuels. Regarding heat emission from radial blanket assemblies, it reached around the boundary condition (2.6kW/Assembly) for the design study in FaCT project. Meanwhile, FRs without radial blanket increase after 2090; although the quantity of MAs are enough for the criteria, it may need additional measure for high decay heat emission from radial blanket assemblies because of the recovered MAs with high 
decay heat in FR cycle. Though only an example scenario is provided here, it can be said that the measure to improve proliferation resistance of blanket SF by MA doping should be careful for both proliferation resistance requirements and realistic constraints of fuel cycle operation at the same time.

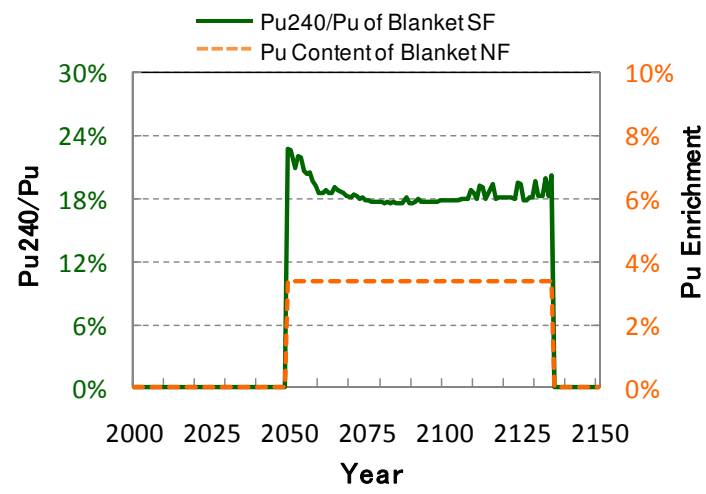

Fig. 19. Pu 240/Pu in blanket SF of all MOX blanket fuel case
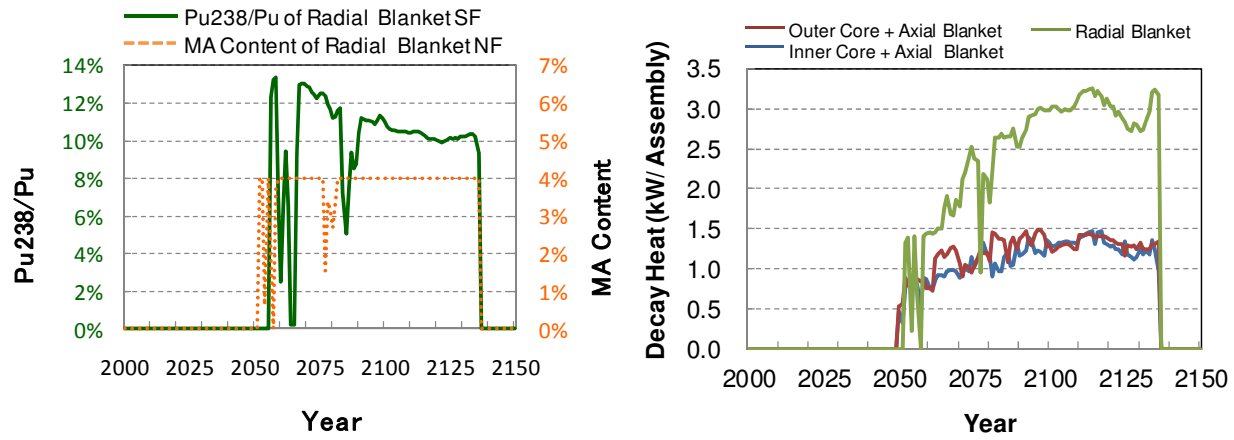

Fig. 20. Pu 238/Pu of blanket SF and decay heat emission from assemblies in all blanket fuels with MA doping case

In general, the measure except for "all blanket with MA" case in this scenario study to improve proliferation resistance of blanket spent fuel in FR can achieve their purposes unless they are reviewed from broader feasibility including R\&D difficulties, adverse effect on economics, and other logistics issues, etc. Accordingly, it should be paid attention to the by-effects described above in case such measures are applied as a practical manner in future.

\subsubsection{Advanced topics and latest situation of Japanese nuclear energy}

The authors will explain the more realistic supposition in the scenario analyses with the $\mathrm{Pu}$ possession by utility companies. Furthermore, a scenario study for the influence of accident in Fukushima Daiichi occurred after a gigantic earthquake hit several prefectures in eastern part of Japan in March, 2011. 
Conventional scenario analyses usually consider the Japanese nuclear power plants as one block; therefore, they ignore both the property right of nuclear material and/or constrains based on the matter of contracts between companies in general. Regarding the detailed analysis dealing Pu recycling in LWR with full MOX core at Ohma by J-Power, the analysis tool can reflect plutonium transfer contracts between J-power and 7 electric utilities (Tohoku, Tokyo, Chubu, Hokuriku, Chugoku, Shikoku, and Kyushu) for the initial loading core. If the future Pu balance was considered from worm's-eye view, such kinds of transfers should be counted. An example of rough estimation of $\mathrm{Pu}$ transfers during "Pu recycling in LWR period" in Japan between electricity utilities by SCM code was shown in Figure 21. Besides the $\mathrm{Pu}$ demands in Figure 22, other $\mathrm{Pu}$ is needed for FR deployment and running stock for operation from the discrepancy of recovered $\mathrm{Pu}$ and $\mathrm{Pu}$ demand for $\mathrm{Pu}$ recycling in LWR. J-power may have to gather $\mathrm{Pu}$ from other electricity utilities for $\mathrm{Pu}$ recycling in Ohma plant.

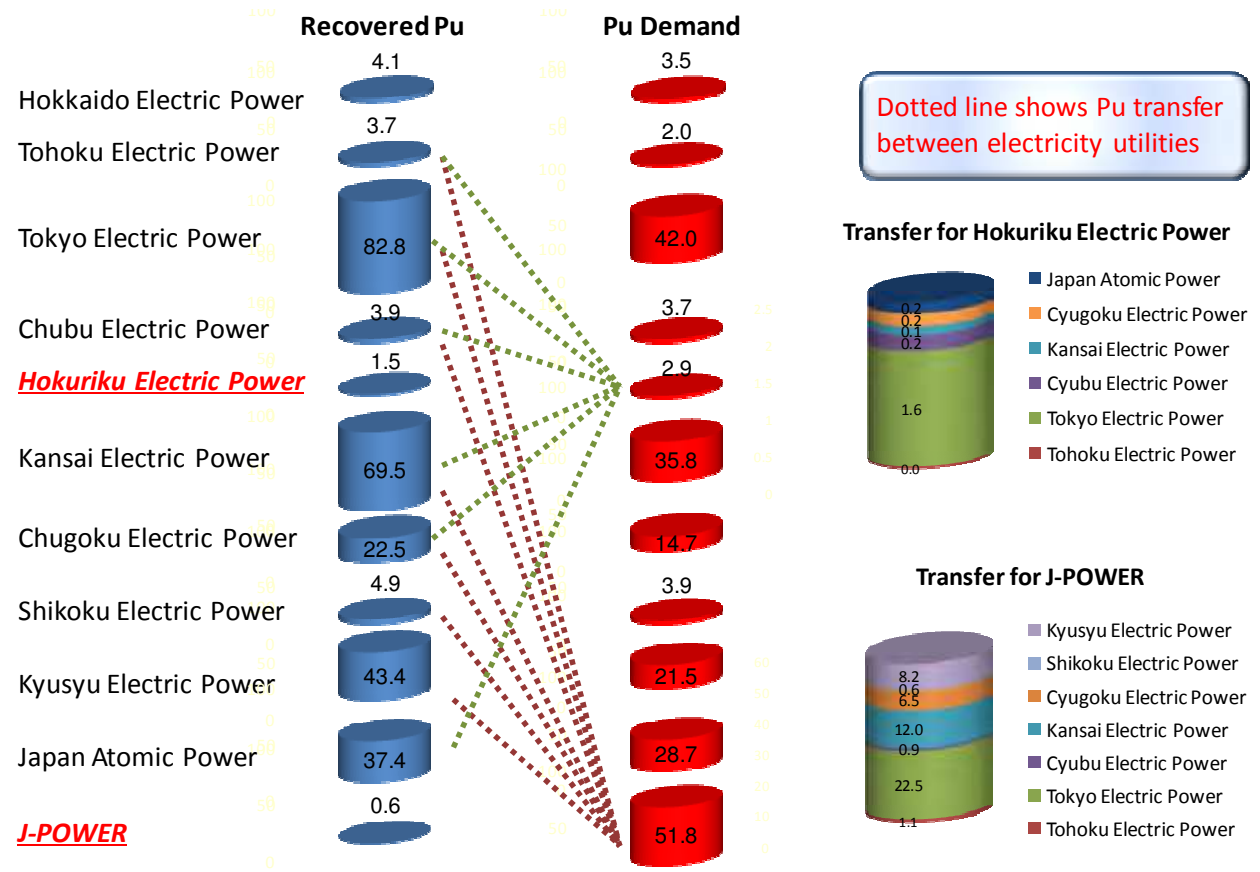

Fig. 21. Example of Pu transfer estimation during "plutonium recycling in LWR" period in Japan 
A larger earthquake ever recorded in Japanese history hit northern eastern part of Japan on March 11, 2011, the record-breaking tsunami occurred subsequent to the earthquake caused severe accident of Fukushima Daiichi Nuclear Power Station. Concerning the influence of the accident on Japanese nuclear policies, it is too early to say something definitive because the accident has not finalized yet and the governmental argument on future energy policies has not started. Presently, the authors can suggest the role and flexibility of FR cycle according to the series of analyses by SCM code with the following assumptions:

The nuclear power plants involved in Fukushima Daiichi accident (Fukushima-1 No.1 to NO. 4) will not restart,

Though new nuclear power plants will not be constructed in new locations, the existing nuclear power plants other than listed above will be replaced by new nuclear power plants.

The breeding requirement for FR cycle system will be reduced under the assumption of both withdrawals from several nuclear power plants and deployment of next generation LWRs with longer plant lifetime. The result also indicated that FR cycle will be FR with break-even core from the beginning of installation without rapid breeding needs. It will curb fuel cycle cost through the reduction of mass-flow by the usage of high burnup fuel. The flexibility of breeding capability in FR leads us to adapt both higher nuclear capacity and lower nuclear capacity to some extent by giving weight to economics or breeding in the coexistence of LWR and FR nuclear fleet in transient state.

\section{Conclusion}

The authors tried to provide overall path to nuclear energy system with FR and related fuel cycle facilities firstly. Along with to the R\&D effort to improve economic competitiveness, safety and reliability, and several ideas for future uncertainties the fissile material breeding ability of FR cycle system and the potential of FR core with fast neutron to burn broader isotopes, FR is major option for electricity supply for future Japan.

Secondly, the recent achievement in SCM code as the system dynamic analysis tool in FaCT project. Because of the sufficient flexibility of the newly developed analysis code based on object-oriented design, it can meet both "single plant characteristic evaluation" and "Japanese whole nuclear fleet scenario study until 22nd century". The code will be used as an infrastructure of future nuclear energy system in Japan.

In addition to the fact that a nuclear energy system development usually needs a long leadtime for decades, it was important that the development of the current LWR cycle and R\&Ds may have an influence on successive nuclear energy system including FR cycle through the supply chain of nuclear energy system. Nuclear energy utilization and development become a matter of argument in reaction to the occurrence of Fukushima Daiichi's accident, it should be keep in mind that today's decision on the directions of nuclear energy R\&D under influence of the fresh memory of accident may make a difference in far future as well as that in immediate future.

\section{Acknowledgment}

The authors would like to express their deep gratitude to both Mr. Heta and Mr. Yasumatsu of NESI Inc. for their contribution for the various works. The authors also would like to express admiration for Mr. Ishii and other members of Mizuho Information and Research for their high performance in the development of the analysis code. 


\section{References}

Grover R. B. and Chandra S. (2004). A Strategy for Growth of Electrical Energy in India, DAE Report No.10

Japan Atomic Energy Agency. (2011), JAEA R\&D Review 2010, What Core Design Prevents Nuclear Proliferation? -Commercial FBR Core Study Focusing on a Material Barrier-, 12, (CD-ROM)

Japan Atomic Energy Agency/Japan Atomic Power Company. (2009), Fast Reactor Cycle Technology Development Project (FaCT Project) - Phase I (Interim Report) -, JAEAEvaluation-2009-003, (May 2009) (in Japanese)

Japan Atomic Energy Commision. (2005), Framework for Nuclear Energy Policy, (October 2005)

Japan Atomic Energy Commision. (2010), Appropriateness of the „Plutonium Utilization Plans (FY2010)“ Announced by Electric Utilities and the IAEA, (March 2010), AEC HP , Apr 12, 2011, Available from:

<http://www.aec.go.jp/jicst/NC/about/kettei/seimei/100323_e.pdf>

Kawashima, K. et al. (2010). Fast reactor Core Design Considerations from Proliferation Resistance Aspects, Proceedings of FR09, Kyoto, Japan, December 7-11, 2009

Ministry of Economy, Trade and Industry. (2010), Basic Energy Plan (June 2010), pp. 27, 31, 32 (in Japanese)

Ministry of Economy, Trade and Industry. (2010), FY2010 Electric Power Supply Plan (March 2010) (in Japanese)

Ministry of Education, Trade and Technology. (2010),Seinoumokuhyou no tasseido hyouka (1)-(3), MEXT HP, April 12, 2011, Available from:

http://www.mext.go.jp/b_menu/shingi/chousa/kaihatu/008/shiryo/_icsFiles/ afieldfile/2010/12/28/1300643_1.pdf, http://www.mext.go.jp/b_menu/shingi/chousa/kaihatu/008/shiryo/_icsFiles/ afieldfile/2010/12/28/1300643_2.pdf,

http://www.mext.go.jp/b_menu/shingi/chousa/kaihatu/008/shiryo/_icsFiles/ afieldfile/2010/12/28/1300643_3.pdf

Nuclear energy subcommittee of Electricity Industry Committee of Advisory Committee for Natural Resources and Energyin Ministry of Economy, Trade and Industry. (2006), Japan's Nuclear Energy National Plan (August 2006), pp. 63 (in Japanese)

OECD/IEA. (2008), Energy Technology Perspectives 2008

OECD/IEA. (2009). World Energy Outlook 2009

OECD/IEA. (2010). Energy Technology Perspectives 2010

OECD/NEA \& IAEA. (2010). Uranium 2009: Resources, Production and Demand

Ohki, S. et al., (2008). FBR core concepts in the FaCT Project in Japan, Proceedings of Physor '08, Interlaken, Switzerland, September 14-19, 2008

Sagayama Y. (2010), Long-term Nuclear Energy Development Scenario for Sustainable Energy Supply, Electrical Review, Vol.556 (December 2010) (in Japanese)

The advisory committee for Natural Resources and Energy's subcommittee to study costs and other issues, The report of the Advisory Committee for Natural Resources and Energy's subcommittee to study costs and other issues, Japan. (2004)(in Japanese). 
Xu M. (2005). Status and Prospects of Sustainable Nuclear Power Supply in China, GLOBAL 2005, Tsukuba, Japan, Oct. 9-13 2005 


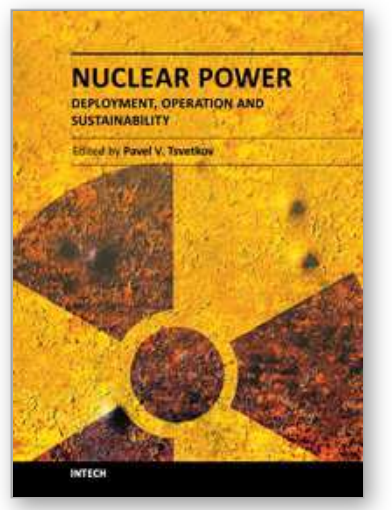

\author{
Nuclear Power - Deployment, Operation and Sustainability \\ Edited by Dr. Pavel Tsvetkov
}

ISBN 978-953-307-474-0

Hard cover, 510 pages

Publisher InTech

Published online 09, September, 2011

Published in print edition September, 2011

We are fortunate to live in incredibly exciting and incredibly challenging time. Energy demands due to economic growth and increasing population must be satisfied in a sustainable manner assuring inherent safety, efficiency and no or minimized environmental impact. These considerations are among the reasons that lead to serious interest in deploying nuclear power as a sustainable energy source. At the same time, catastrophic earthquake and tsunami events in Japan resulted in the nuclear accident that forced us to rethink our approach to nuclear safety, design requirements and facilitated growing interests in advanced nuclear energy systems. This book is one in a series of books on nuclear power published by InTech. It consists of six major sections housing twenty chapters on topics from the key subject areas pertinent to successful development, deployment and operation of nuclear power systems worldwide. The book targets everyone as its potential readership groups - students, researchers and practitioners - who are interested to learn about nuclear power.

\title{
How to reference
}

In order to correctly reference this scholarly work, feel free to copy and paste the following:

Hiroki Shiotani, Kiyoshi Ono and Takashi Namba (2011). Characteristic Evaluation and Scenario Study on Fast Reactor Cycle in Japan, Nuclear Power - Deployment, Operation and Sustainability, Dr. Pavel Tsvetkov (Ed.), ISBN: 978-953-307-474-0, InTech, Available from: http://www.intechopen.com/books/nuclear-powerdeployment-operation-and-sustainability/characteristic-evaluation-and-scenario-study-on-fast-reactor-cycle-injapan

\section{INTECH}

open science | open minds

\section{InTech Europe}

University Campus STeP Ri

Slavka Krautzeka 83/A

51000 Rijeka, Croatia

Phone: +385 (51) 770447

Fax: +385 (51) 686166

www.intechopen.com

\section{InTech China}

Unit 405, Office Block, Hotel Equatorial Shanghai

No.65, Yan An Road (West), Shanghai, 200040, China 中国上海市延安西路65号上海国际贵都大饭店办公楼405单元

Phone: +86-21-62489820

Fax: +86-21-62489821 
(C) 2011 The Author(s). Licensee IntechOpen. This chapter is distributed under the terms of the Creative Commons Attribution-NonCommercialShareAlike-3.0 License, which permits use, distribution and reproduction for non-commercial purposes, provided the original is properly cited and derivative works building on this content are distributed under the same license. 